\title{
An environmental friendly catalyst for the high temperature shift reaction
}

\author{
G. C. Araujo and M. C. Rangel
}

Instituto de Quimica, Universidade Federal da Bahia, Campus Universitário de Ondina, Federação. 40170-280 Salvador, Bahia, Brazil

The need for environmental protection has demanded the searching nontoxic catalysts easily handled and discarded. This work deals with the use of aluminum as a substitute of chromium, in iron- and copper-based catalysts for the high temperature shift reaction. Catalysts were prepared in the commercial form (hematite) and was evaluated in more severe operational conditions than the usual industrial one (e.g. steam to carbon ratios, $R$, lower than 0.6). It was found that aluminum can replace chromium in these catalysts leading to better catalytic properties as compared to chromium. The catalyst has the advantage of being non toxic and can work in low amounts of steam.

\section{INTRODUCTION}

The production of hydrogen from the natural gas or naphtha feedstock is usually increased by means of the water gas shift reaction (WGSR) [1]:

$$
\mathrm{CO}_{(\mathrm{g})}+\mathrm{H}_{2} \mathrm{O}_{(\mathrm{g})} \rightleftarrows \mathrm{CO}_{2}+\mathrm{H}_{2} \mathrm{O}_{(\mathrm{g})} \quad \Delta \mathrm{H}=-41.1 \mathrm{~kJ} \cdot \mathrm{mol}^{-1}
$$

which is also an important stage in the commercial production of hydrogen. This reaction is a reversible and exothermic one and thus is favored by low temperatures and excess of steam. However, it requires high temperatures to achieve rates high enough for industrial applications. Therefore, the WGSR is often carried out in two steps, the first being performed in the range of $320-450^{\circ} \mathrm{C}$ (named high temperature shift, HTS). In the second stage (known as low temperature shift, LTS), carbon monoxide is removed from the feed stream in thermodynamically favorable conditions in the range of $200-250^{\circ} \mathrm{C}$ [1].

The HTS stage is often carried out over catalysts of chromium-doped iron oxides, available as hematite. The catalyst is reduced in situ to produce magnetite which is found to be the active phase. In ammonia plants, the reduction is performed with a gaseous mixture of carbon monoxide and dioxide, hydrogen and nitrogen. This reaction is highly exothermic and should be carefully controlled to prevent damage to the reactor or to the catalyst. The production of metallic iron should be particularly avoided since it may catalyze the hydrocarbon formation $[1,2]$. In order to assure the magnetite stability in industrial processes, large amounts of steam are used. However, this procedure increases the operational costs and thus new 
systems that do not generate metallic iron, even at low contents of steam, are demanded [3].

In spite of the chromium-doped hematite catalysts have shown high stability in performance, they have been recently modified by the addition of small amounts of copper, resulting in even more active and selective catalysts. However, because of environmental restrictions concerning the discarding of chromium compounds, the search for non-toxic catalysts which could be easily handled and discarded is much needed.

With this goal in mind, this work deals with the replacement of chromium by aluminum in HTS catalysts. In order to save the energy related to the steam consumption, the catalysts were also evaluated in more severe operational conditions than the industrial one, e.g. lower steam to carbon ratios.

\section{EXPERIMENTAL}

The reagents used were analytical grade.

The catalysts were prepared by copreciptation techniques at room temperature, followed by heating at $500^{\circ} \mathrm{C}$ for $2 \mathrm{~h}$ under nitrogen flow $(100$ $\mathrm{ml}$. $\min ^{-1}$ ). Four samples were prepared: (i) with aluminum and copper (HAC sample); (ii) with only aluminum (HA sample); (iii) with only copper (HC sample) and (iv) without any dopant ( $\mathrm{H}$ sample). For all samples an iron to the dopant molar ratio of 10 was used.

The aluminum and copper-based catalyst was prepared by adding aqueous solutions of $\mathrm{Fe}\left(\mathrm{NO}_{3}\right)_{3} .9 \mathrm{H}_{2} \mathrm{O}(1 \mathrm{~N})$ and $\mathrm{Al}\left(\mathrm{NO}_{3}\right)_{3} .9 \mathrm{H}_{2} \mathrm{O}(0.1 \mathrm{~N})$ and a concentrated $(25 \% \mathrm{w} / \mathrm{w})$ aqueous solution of ammonium hydroxide to a beaker with water, under stirring. The final $\mathrm{pH}$ was adjusted to 11 and the system was kept under stirring for additional 30 min. The sol produced was centrifuged $(2000 \mathrm{rpm}, 5 \mathrm{~min})$ followed by a water rinsing to remove the nitrate ions from the starting material. After a second centrifugation step, the gel was impregnated with an aqueous solution of $\mathrm{Cu}\left(\mathrm{NO}_{3}\right)_{2} .3 \mathrm{H}_{2} \mathrm{O}(0.06 \mathrm{~N})$ for $24 \mathrm{~h}$ under stirring, centrifuged again and dried in an oven at $120^{\circ} \mathrm{C}$. The same procedure were used to prepare the other samples. For the catalysts without copper, the gel was kept in pure water for $24 \mathrm{~h}$, under stirring, in order to simulate the same experimental conditions used to prepare the other samples.

The qualitative analysis of nitrate was performed by adding about $1 \mathrm{ml}$ of concentrated sulfuric acid to $10 \mathrm{ml}$ of the sobrenadant after centrifugation. The formation of $[\mathrm{Fe}(\mathrm{NO})]^{2+}$ was detected by a brown ring [4]. The absence of nitrate in the solid was confirmed by infrared spectroscopy in the range of $4000-650 \mathrm{~cm}^{-1}$ using a Shimadzu model IR-430 spectrometer and KI discs. The metal contents were determined by inductively coupled plasma atomic emission by using an model Arl 3410 equipment. X-ray diffractograms were recorded at room temperature with a Shimadzu model XD3A instrument using $\mathrm{Cu} \mathrm{K} \alpha$ radiation generated at $30 \mathrm{kV}$ and $20 \mathrm{~mA}$. The surface area (BET method) was measured in a Micromeritics model TPD/TPO 2900 equipment on samples previously heated under nitrogen $\left(150^{\circ} \mathrm{C}, 2 \mathrm{~h}\right)$. The temperature 
programmed reduction (TPR) was performed in the same equipment, using a $5 \% \mathrm{H}_{2} / \mathrm{N}_{2}$ mixture. The copper area was measured in a CG-2001 equipment using the $\mathrm{N}_{2} \mathrm{O}$ pulse technique $[5,6]$. X-rays microanalysis were performed in a Noran microprobe coupled to a model JSM-T300 microscope operating at 20-30KV.

The catalyst performance was evaluated using $0.2 \mathrm{~cm}^{3}$ of powder within 50 and +325 mesh size and a fixed bed microreactor consisting of a stainless tube, providing there is no diffusion effect. All experiments were carried out under isothermal condition $\left(370^{\circ} \mathrm{C}\right)$ and at atmospheric pressure, employing a gas mixture with composition around $10 \% \mathrm{CO}, 10 \% \mathrm{CO}_{2}, 60 \%$ $\mathrm{H}_{2}$ and $20 \% \mathrm{~N}_{2}$. It was used several steam to gas molar ratios: $0.2,0.4$ and 0.6. The gaseous effluent was analyzed by on line gas chromatography, using a CG-35 instrument. A commercial catalyst, based on chromium, copper and iron oxides, was used to compare the performance of the samples prepared in this work. In order to determine the role of copper in these catalysts, a mechanical mixture of the sample with aluminum (HA sample) and copper oxide was also evaluated. In this case, the catalyst tests were run at $200^{\circ} \mathrm{C}$ because of the high tendency of copper of sintering at $370^{\circ} \mathrm{C}$ [1]. After each experiment, the Fe(II) content in the catalysts was determined to follow the iron reduction under reaction atmosphere. Samples were dissolved in concentrated chloridric acid, under carbon dioxide atmosphere and then titrated with potassium dichromate [7].

\section{RESULTS AND DISCUSSION}

As shown in Figure 1, hematite was detected in the fresh catalysts while magnetite was found in the used catalysts; aluminum tends to impair crystallization whereas copper tends to favor it. No other phase besides hematite and magnetite was detected.

The presence of either aluminum or the two dopants increased the surface area of the solids (Table 1), which was not affected by doping the solid with copper alone. For the used catalysts, aluminum increased the surface area while copper decreased it. The characteristics of the spent catalysts did not show any significant dependence on the steam to gas molar ratio $(R)$ used in the test reaction. The catalyst reduction strongly decreased the surface area, showing that the phase change is followed by a coalescence of particles and/or porous. Aluminum increased the copper areas showing that this metal prevents copper sintering. The aluminum presence on the surface was confirmed by X-ray microanalysis.

The TPR curves of hematite (Figure 2) showed one peak at $510^{\circ} \mathrm{C}$, due to magnetite formation and another around $770^{\circ} \mathrm{C}$, attributed to the formation of metallic iron [8]. In the aluminum-doped sample, the first peak was shifted to lower temperatures $\left(400^{\circ} \mathrm{C}\right)$, whereas the higher temperature peak was not affected; this behavior shows that this metal eases the formation of the active phase but does not affect its stability. The copper-doped catalyst showed a TPR curve with a peak around $210^{\circ} \mathrm{C}$, assigned to metallic 
copper [9] and other peaks around 230 and $600^{\circ} \mathrm{C}$; these TPR peaks show that copper favors the active phase formation and destruction. The aluminum and copper-doped solid showed a curve with the characteristic peak due to magnetite formation displaced to $300^{\circ} \mathrm{C}$ and the peak related to metallic iron at $770^{\circ} \mathrm{C}$. It means that the synergetic effect of the dopants is

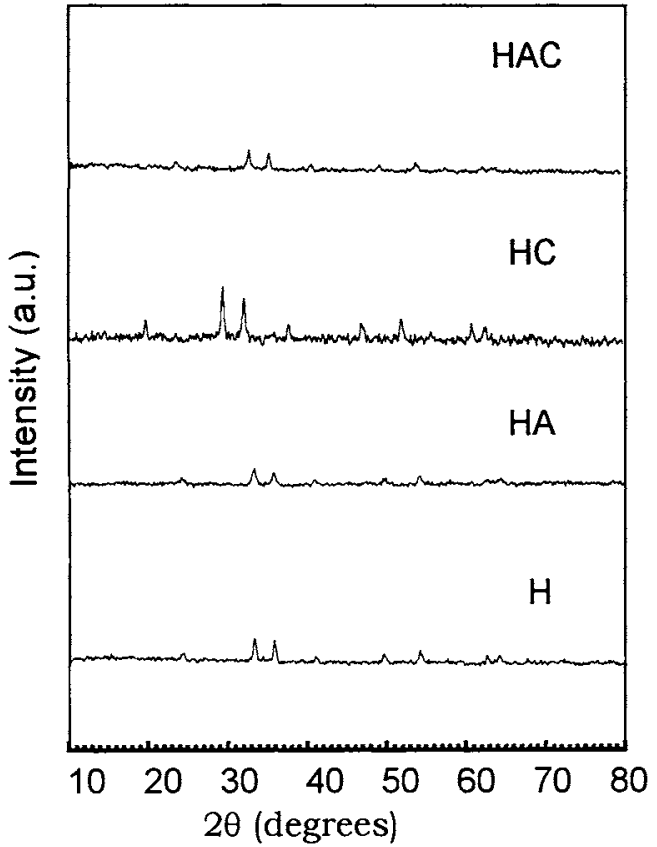

(a)

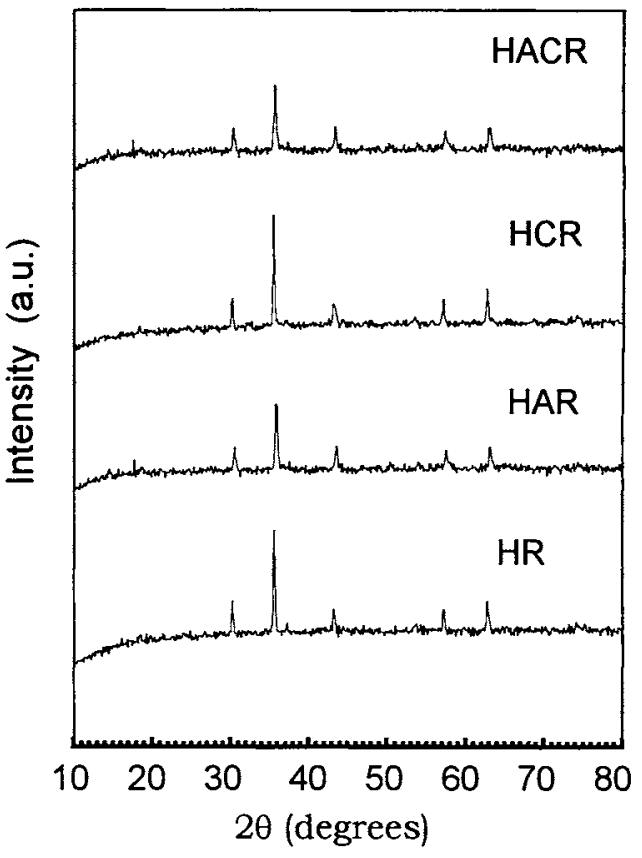

(b)

Figure 1. X-ray diffractograms of (a) fresh and (b) used catalysts. $H=$ hematite; $\mathrm{A}=$ aluminum and $\mathrm{C}=$ copper

Table 1

Surface area (Sg) and copper area of the samples

\begin{tabular}{l|c|rrr|c}
\hline Sample & $\begin{array}{c}\mathrm{Sg}\left(\mathrm{m}^{2} \cdot \mathrm{g}^{-1}\right) \\
\text { (before reaction) }\end{array}$ & \multicolumn{3}{|c|}{$\mathrm{Sg}\left(\mathrm{m}^{2} \cdot \mathrm{g}^{-1}\right)$} & $\begin{array}{c}\text { Copper area } \\
\text { (after reaction) } \\
\left(\mathrm{m}^{2} / \mathrm{g}\right)\end{array}$ \\
& & $\mathrm{R}=0.6$ & $\mathrm{R}=0.4$ & $\mathrm{R}=0.2$ & (fresh catalysts) \\
\hline $\mathrm{H}$ & 27 & 8 & 9 & 9 & -- \\
$\mathrm{HA}$ & 59 & 24 & 25 & 28 & -- \\
$\mathrm{HC}$ & 26 & 6 & 4 & 6 & 39 \\
$\mathrm{HAC}$ & 86 & 17 & 22 & 24 & 44 \\
\hline
\end{tabular}

$\mathrm{R}=$ steam/process gas (molar)

to ease magnetite formation but not to affect the production of metallic iron. The commercial catalyst showed a TPR curve with peaks around 270,340 and $750^{\circ} \mathrm{C}$, showing that chromium is less effective in prevent the active phase formation and destruction. 
All catalysts were active to HTS reaction, as shown in Table 2. Aluminum leads to a slight increase in activity, which is due to a textural effect. On the other hand, copper increased both the activity and the activity per area, showing that it acts as a structural promoter. The copper area values, as well as the TPR results, suggest that the higher activity of the copper promoted catalyst is due to an increase of the number of active sites; it is well known that copper is also active in the HTS reaction [1,2]. However, the mechanical mixture of the sample with aluminum (HA) and copper oxide $\left(3 \times 10^{-4}\right.$ mol.g $\left.\mathrm{g}^{-1} \mathrm{~h}^{-1}\right)$ showed a lower activity than the HAC sample $\left(7 \times 10^{-4} \mathrm{~mol}\right.$. $\left.\mathrm{g}^{-1} \cdot \mathrm{h}^{-1}\right)$ at $200^{\circ} \mathrm{C}$, suggesting that there is probably an electronic effect of copper.

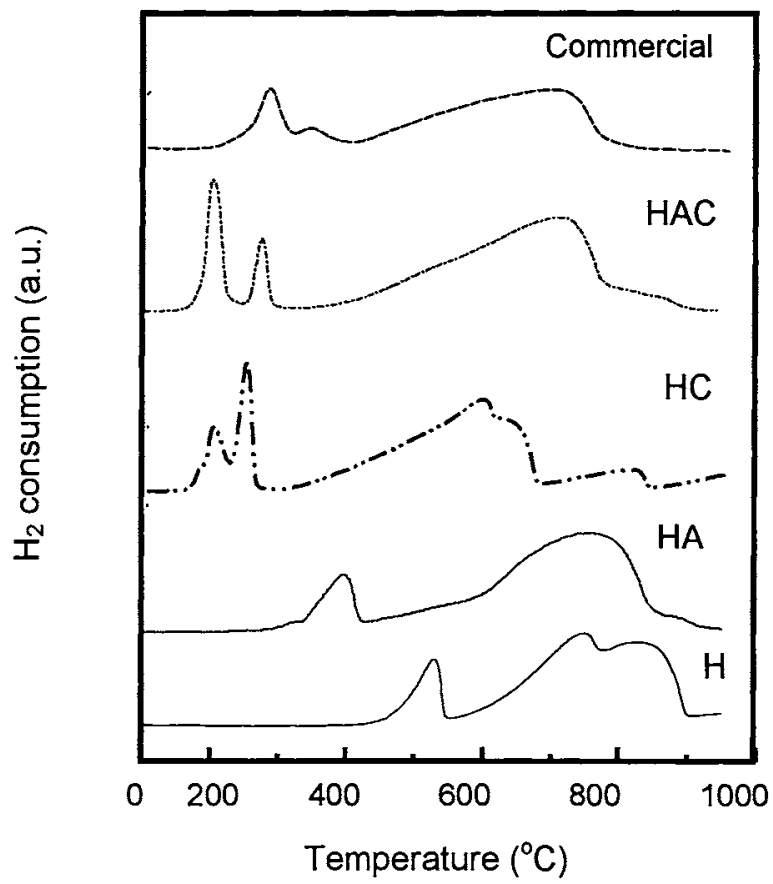

Figure 2. TPR catalysts. $\mathrm{H}=$ hematite; $\mathrm{A}=$ aluminum and $\mathrm{C}=$ copper

The experiments carried out at lower steam to gas ratio showed that the catalysts can work at $\mathrm{R}=0.4$ without any damage to both activity or selectivity to carbon dioxide. At $\mathrm{R}=0.2$, however, the activity and selectivity strongly decreased with the amount the steam. The analysis of the used catalysts showed that this behavior was likely due to the lower $\mathrm{Fe}(\mathrm{II}) / \mathrm{Fe}$ (III) ratio, which means a lower amount of the active sites. Therefore, one can assume that under lower $\mathrm{R}$ larger amounts of metallic iron was produced and hydrocarbon formation was catalyzed.

The catalyst with both dopants showed higher activity than a chromium and copper-doped commercial catalyst $\left(25 \times 10^{-4} \mathrm{~mol}^{-1} \cdot \mathrm{h}^{-1}\right)$. This sample produces the active phase more easily than the other catalysts, shows resistance to a further magnetite reduction and can work at severe conditions, that is, low steam to process gas ratio. 
Table 2

Catalytic activity (a) and selectivity (S) of the samples

\begin{tabular}{|c|c|c|c|c|c|c|c|c|c|}
\hline \multirow[t]{2}{*}{ Sample } & \multicolumn{3}{|c|}{$\begin{array}{c}\operatorname{ax10^{4}} \\
\left(\mathrm{mol}^{-1} \mathrm{~g}^{-1} \cdot \mathrm{h}^{-1}\right)\end{array}$} & \multicolumn{3}{|c|}{$\begin{array}{c}\mathrm{a} / \mathrm{Sgx} 10^{5} \\
\left(\mathrm{~mol} \cdot \mathrm{m}^{-2} \cdot \mathrm{h}^{-1}\right)\end{array}$} & \multicolumn{3}{|c|}{ Selectivity (\%) } \\
\hline & $\mathrm{R}=0.6$ & $\mathrm{R}=0.4$ & $\mathrm{R}=0.2$ & $R=0.6$ & $\mathrm{R}=0.4$ & $\mathrm{R}=0.2$ & $R=0.6$ & $\mathrm{R}=0.4$ & $\mathrm{R}=0.2$ \\
\hline$\overline{\mathrm{H}}$ & $\overline{7}$ & $\overline{6}$ & 5 & 9 & $\overline{7}$ & 6 & 50 & 50 & 20 \\
\hline HA & 9 & 8 & 6 & 4 & 3 & 2 & 60 & 20 & 10 \\
\hline $\mathrm{HC}$ & 24 & 23 & 16 & 40 & 58 & 27 & 80 & 60 & 60 \\
\hline HAC & 34 & 34 & 17 & 20 & 15 & 7 & 70 & 70 & 80 \\
\hline
\end{tabular}

$\mathrm{R}=$ steam to gas molar ratio

\section{CONCLUSIONS}

The presence of both aluminum and copper in hematite-based catalysts to HTS reaction favors the formation and stability of the active phase. Aluminum acts as textural promoter and copper acts as a structural one. The aluminum, copper-doped hematite catalyst is more active than a commercial catalyst. Therefore, aluminum is a promising dopant to replace chromium in HTS catalysts since it shows two important features: first, it is non toxic, in comparison to the high chromium toxicity, and second it leads to better HTS catalyts as compared to the chromium-doped ones.

\section{ACKOWLEDGEMENT}

The authors thank the financial support from CNPq, FINEP and $\mathrm{CNPq} / \mathrm{PADCT}$.

\section{REFERENCES}

1. H. Bohlbro, An Investigation on the Kinetics of the Conversion of Carbon Monoxide with Water Vapor over Iron Oxide based Catalysts, The Haldor Topsoe Laboratory, Vedback, 1960.

2. Newsome, D. S., Catal. Rev.- Sci. Eng., 21 (1980) 275.

3. M. V. Twigg, Catalyst Handbook, Wolfe Scientific Books, London, 1970.

4. F. Fergl, V. Anger and R. E. Oesper, Inorganic Analysis, Elsevier, Amsterdam, 1972.

5. C. R. F. Lund, J. J. Schorfheide and J. A. Dumesic, J. Catal., 57 (1979) 103.

6. M. J. Luys, P. H. van Oeffelt, P. Pieters and R. Terven, Catalysis Today, 10 (1991) 283.

7. A. I. Vogel, Quantitative Inorganic Analysis, Longman, London, 1961.

8. J. C. Gonzalez, M. G. González, M. A. Laborde and N. Moreno, Appl. Catal., 20 (1986) 3.

9. S. Pinna, T. Fantinel, G. Strukul, A. Benedetti, and N. Pernicone, Appl. Catal., 49 (1997) 341. 